\title{
Microsurgical Reconstruction with Free Osteocutaneous Fibular Flap for Mandibular Osteoradionecrosis with Pathological Fracture: A Case Report
}

\author{
Prashant Moon ${ }^{1 *}$, Bharat Bhushan Garg² \\ ${ }^{1}$ Consultant plastic and Reconstructive Microsurgeon, krishna Hospital and Research Centre, Haldwani ,India \\ ${ }^{2}$ Consultant Radiodiagnosis, krishna hospital and research centre, Haldwani, India
}

Submission: October 11, 2017; Published: October 17, 2017

*Corresponding author: Prashant Moon, Consultant Plastic and reconstructive micro surgeon, Smile Train, Haldwani, India, Tel: 9100423529 ; Email: prashantemoon@gmail.com

\begin{abstract}
Osteoradionecrosis of mandible is a complication related to radiation to the neck and face. Pathological fracture in osteoradionecrosis is attributed to trivial trauma in already weak bone. Hyper baric oxygen therapy and Medical management is useful in osteoradionecrosis of mandible without pathological fracture. Pathological fracture of the mandible body related to osteoradionecrosis is a difficult problem to treat. Micro vascular reconstruction of mandible with vascularised free fibula flap is the best treatment option available for such condition. We describe the case of pathological fracture in a case of osteoradionecrosis of mandible.
\end{abstract}

Keywords: Osteoradionecrosis; Free fibula flap; Micro vascular and reconstruction

\section{Introduction}

Osteoradionecrosis is the long term and most serious side of radiotherapy. The definition of osteoradionecrosis is generally accepted as presence of exposed bone in an irradiated field, which fails which to heal within a three-month a period [1]. Treatment of osteoradionecrosis is a challenging problem. There is a variety of treatment options and no universal approach to management, as this depends on institutional or individual experiences. Early case of osteoradionecrosis treated with hyper baric oxygen therapy, antibiotics, tocopherol and pentaxyphyllin [2]. Conservative debridement may be necessary to remove spicules of devitalised bone particularly if the adjacent tongue is abraded. Patients who have osteoradionecrosis are traditionally treated with HBO alone or combined with debridement. Segmental mandibulectomy and reconstruction are necessary in patient with severe osteoradionecrosis who do not improve with conservative treatment $[3,4]$.

\section{Case Report}

We report a case of 72 year old male patient with pathological fracture with draining cutaneous sinus. Patient had diagnosed with hypo- pharyngeal carcinoma 10 year back. Patient had received radiotherapy and chemotherapy immediately after diagnosis. Patient was complaining of difficult and pain while opening of mouth 6 month back. Patients had developed swelling at lower border of mandible which after few days ruptures with pus discharge. Patients had no history of trauma to face, dental extraction, or any oral surgery. On clinical examination patient had scared and lusterless oral mucosa. There was a draining sinus over owner border of cheek. Mandibular crepitus with severe tenderness was present. Patient was first evaluated for any possible recurrence. Ct scan was done to know about site of fracture and extent of osteomyelitis. PET CT scan and Biopsy was done to rule out malignancy or recurrence.

Pus culture was done suggestive of streptococcal infection sensitive to ampicillin Antibiotic started 1 week before actual procedure. Patient was posted for operation after obtaining physical fitness. Under general anaesthesia lip splitting incision was taken. Wide local excision of draining sinus with fibrosed soft tissue and segmental mandibulectomy was done to obtain healthy bleeding edges of bone and skin. Recipient vessel explored. Facial artery was thrombosed till its origin. External carotid artery was prepared as recipient artery and common facial and external jugular vein was prepared as recipient vein. Measurement of defect of skin and bone done and template 
prepared. Free osteocutaneous free fibula flap harvested under tourniquet control. Adequate vessel and bony preparation were done. Bony fixation was done with titanium plate and screw. Partial inset was given. Arterial and venous anastomoses were done with external carotid artery and common facial vein. Oral cavity closed in layer. Donor site closed primarily. Patient was Discussion

Table 1: Classification of ORN by Marx [3].

\begin{tabular}{|c|c|}
\hline Stage & Description \\
\hline I & Exposed alveolar bone without pathologic fracture, which responds to hyperbaric oxygen therapy \\
\hline II & Disease does not respond to HBOT, and requires sequestrectomy and saucerisation \\
\hline III & Full thickness bone damage or pathologic fracture, usually requires complete resection and reconstruction with free tissue \\
\hline
\end{tabular}

Osteoradionecrosis of facial bone is the rare complication of radiotherapy given for head neck cancer. Mandible is most commonly involved bone in osteoradionecrosis (Table 1). Pathophysiology for osteoradionecrosis is radiation induced hypoxic injury at cellular level. Hypoxic injury leads to tissue break down resulted in chronic non healing ulcer. Obliteration of capillaries and larger vessels along with radiation fibrosis in ischemia of the tissues [5]. Osteoradionecrosis is a possible complication following radiotherapy where an area of bone does not heal from irradiation of bones causes' damage to osteocytes and impairs the blood supply. Incidence osteoradionecrosis is $3.0 \%$ in recent studies [6].

Bone injury can occur through. kept on heparin to prevent thrombosis at anastomosis site. Post operative recovery was uneventful. Patient was discharged on 10th post operative day. Patient was followed for 3 month. Postoperatively patient was kept on pentaxyphyllin and tocopherol.
I. Spontaneous (37\%)

II. Direct trauma (63\%)

a. Tooth extraction

b. related cancer surgery or biopsy

The clinical risk factors of ORN can be divided into local and systemic. Some of the local factors include tumor stage, tumor site, dose or radiation (>50-60 Gy), radiation field, dental extraction and poor oral hygiene, whereas systemic factors include infection, immune deficient states, co-morbidities and malnutrition [7]. Use of IMRT has reduced the incident of osteoradionecrosis in most of studies [8] (Figures 1-3). c. By exposure of oral cavity to the environment

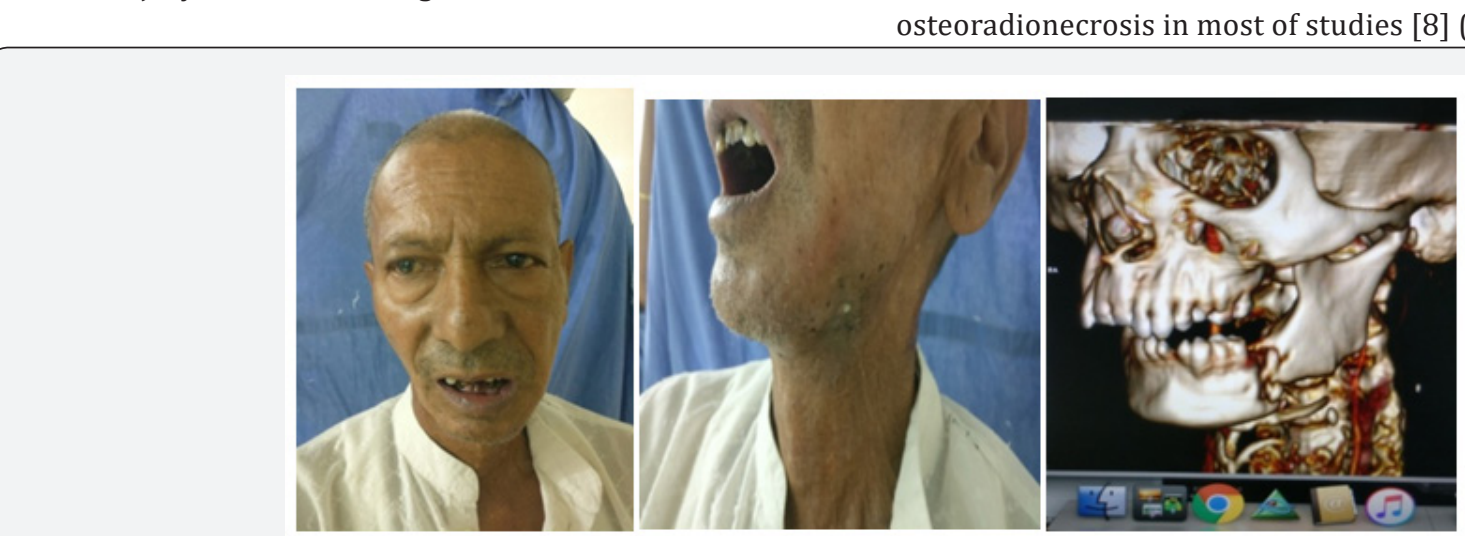

Figure 1: Preoperative photos.

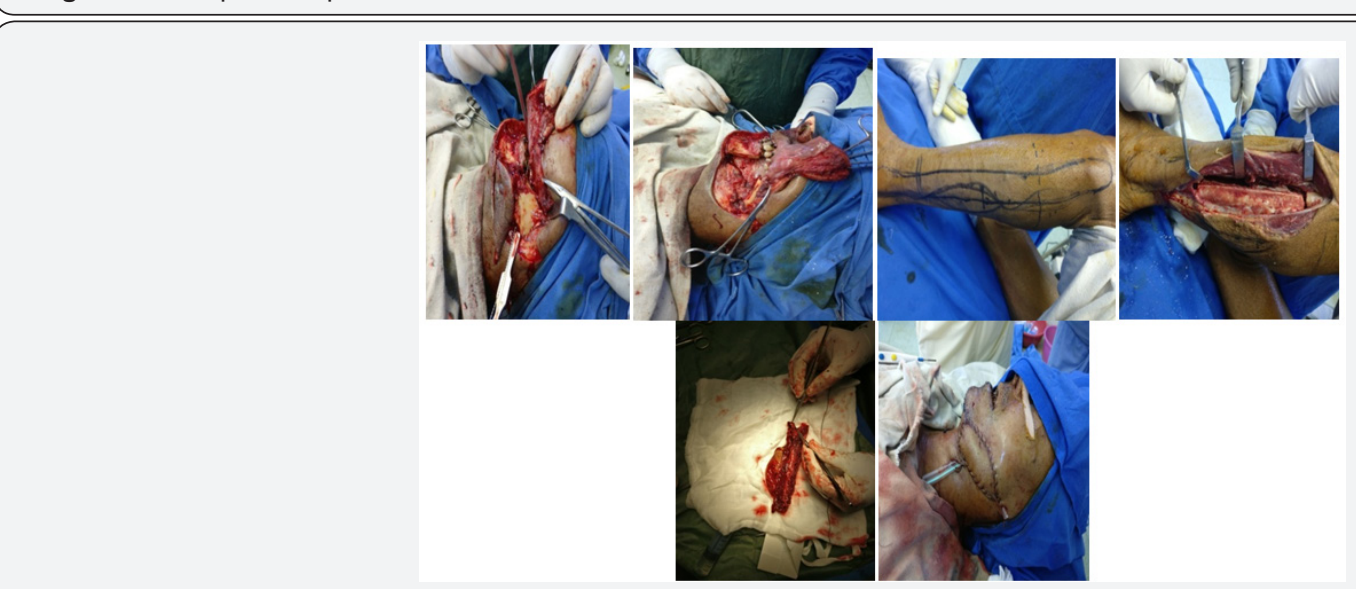

Figure 2: Intraoperative photos. 

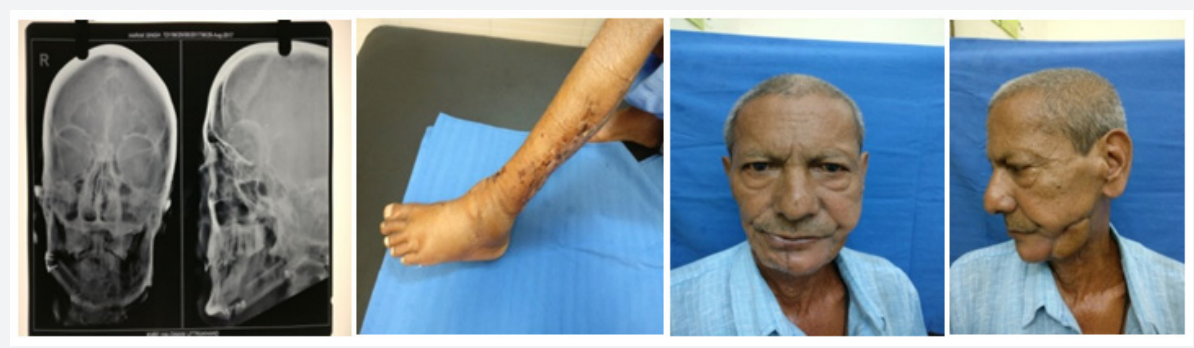

Figure 3: Postoperative photos.

\section{Conclusion}

Early stage ORN is approached conservatively with local wound care, HBO therapy and antibiotic therapy. Stage III patients are treated with aggressive surgical extirpation of all diseased hard and soft tissue, and then immediate reconstruction is performed using free tissue transfer [9]. Free osteocutaneous fibula flap is best reconstructive option to for segmental mandibular body defect.

\section{References}

1. Rayatt Sukh S, Mureau Marc AM, Hofer Stefran OP (2007) osteoradionecrosis of the mandible: Etiology prevention diagnosis and treatment. IJPS 40(12): 65-71.

2. Huan Fan, Soung Min Kim Yun, Ju Cho, Mi Young Eo, Suk Keun Lee, et al. (2014) New approach for the treatment of osteoradionecrosis with pentoxifylline and tocopherol. Biomaterials Research

3. Marx RE (1983) Osteoradionecrosis: a new concept of its Pathophysiology. YJOMS 41: 283-288.
4. Journal of clinical oncology (2004) pp. 4867-4868.

5. Ji Wan kim, Jong Hyun Hwang, kang Min Ahn (2016) Fibular flap for mandible reconstruction in osteoradionecrosis of the jaw: selection criteria of fibula flap. 38 (1): 46.

6. Wahl MJ (2006) Osteoradionecrosis prevention myths. Int J Radiat Oncol Biol Phys 64(3): 661-669.

7. Studer G, Studer SP, Zwahlen RA, Huguenin P, Grätz KW, et al. (2006) Osteoradionecrosis of the Mandible. Strahlenther Onkol 182(5): 283288.

8. Gomez DR, Estilo CL, Wolden SL, Zelefsky MJ, Kraus DH, et al. (2011) Correlation of osteoradionecrosis and dental events with dosimetric parameters in intensity-modulated radiation therapy for head-andneck cancer. Int J Radiat Oncol Biol Phys 81: 207-213.

9. Kayal L, Jayachandran S, Sharma A, Karthikeyan K (2015) Osteoradionecrosis of the mandible: A report of three cases. Clin Cancer Investigation Journal 4: 61-65.

\section{Your next submission with Juniper Publishers} will reach you the below assets

- Quality Editorial service

- Swift Peer Review

- Reprints availability

- E-prints Service

- Manuscript Podcast for convenient understanding

- Global attainment for your research

- Manuscript accessibility in different formats

( Pdf, E-pub, Full Text, Audio)

- Unceasing customer service

Track the below URL for one-step submission https://juniperpublishers.com/online-submission.php 